\title{
MODE SELECTION BY OHMIC LOSSES IN LONGITUDINALLY CORRUGATED CAVITIES OF SUB-THz SECOND-HARMONIC GYROTRONS
}

\author{
T.I. Tkachova', V.I. Shcherbinin ${ }^{1}$, V.I. Tkachenko ${ }^{1,2}$ \\ ${ }^{I}$ National Science Center "Kharkov Institute of Physics and Technology", Kharkiv, Ukraine \\ ${ }^{2}$ V.N. Karazin Kharkiv National University, Kharkiv, Ukraine \\ E-mail: t.i.tkachova@gmail.com,vshch@ukr.net
}

\begin{abstract}
Ohmic wall losses are proposed as a means for improving the mode selection in a cylindrical gyrotron cavity with longitudinal wedge-shaped corrugations. Such losses depend on mode frequency and geometrical parameters of the corrugations. For cavity of the $0.4-\mathrm{THz}$ second-harmonic gyrotron we find the corrugation depth, which corresponds to maximum ohmic losses of the competing modes excited at the first (fundamental) cyclotron resonance, as well as to reasonably low losses of the operating mode. For this depth, we determine the number of corrugations and their width, which ensure the maximum enhancement of the ohmic wall losses of the fundamental modes with respect to those of the operating second-harmonic mode, together with minimum conversion of the operating second-harmonic mode to higher Bloch harmonics. Parameters of the corrugations in hand are practicable.
\end{abstract}

PACS: 84.40.-x, 84.40.Ik, 52.35.Hr

\section{INTRODUCTION}

Nowadays terahertz $(\mathrm{THz})$ electromagnetic radiation finds wide application in science and technology, including bio-medical investigations, high-resolution spectroscopy, meteorology, accelerator physics, security systems, space research and others. Gyrotrons operated at the second harmonic of cyclotron frequency are among the most promising radiation sources for these applications [1]. This is explained by high output power, relatively small size and reasonable cost of present-day sub-THz gyrotrons.

In practice, however, stable operation of the secondharmonic gyrotrons often suffers from the competition between the operating mode and competing modes excited at the first (fundamental) cyclotron harmonic. One way to weaken this unwanted phenomenon is to use longitudinal wall corrugations of cylindrical gyrotron cavity. As is shown in [2], with proper choice of corrugation parameters, including their longitudinal distribution, depth, width and number, it is possible to increase selectively the diffractive losses of the fundamental competing modes of the second-harmonic gyrotron.

On the other hand, wall corrugations induce additional ohmic losses in the cavity and thereby may reduce the efficiency of sub- $\mathrm{THz}$ gyrotron [3]. These losses are frequency-dependent [2, 4]. As a consequence, the corrugation parameters can be selected in such a way as to provide maximum ohmic losses for the first-harmonic modes, together with relatively low losses for the operating second-harmonic mode. It is clear that this effect can be used to improve mode selection in the cavities of second-harmonic gyrotrons. However, up to now, such a possibility remains unexplored.

The aim of this paper is to determine the most optimal parameters of corrugations, which ensure the improved mode selection, acceptable ohmic losses of the operating mode and negligible coupling of azimuthal modes in the cavity of a sub-THz gyrotron operated at the second harmonic of cyclotron frequency.

\section{PROBLEM FORMULATION}

Consider 0.4-THz second-harmonic gyrotron operated in the $\mathrm{TE}_{8,9}$ mode $[2,4,5]$. The gyrotron cavity is in the form of a uniform cylindrical waveguide with longitudinal wedge-shaped corrugations. The transverse cross-section of the cavity is shown schematically in Fig. 1.

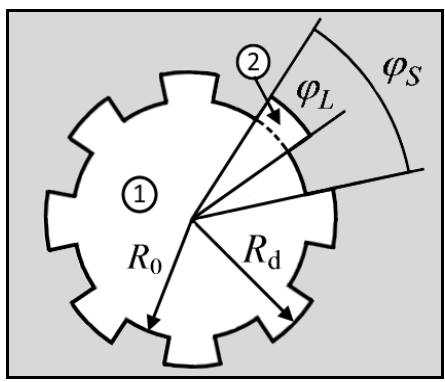

Fig. 1. Transverse cross section of a uniform cylindrical waveguide with longitudinal wedge-shaped corrugations

Electromagnetic field of a TE mode can be expressed in term of the membrane function $\Psi$ subject to the Helmholtz equation

$$
\left(\Delta_{\perp}+k_{\perp}^{2}\right) \Psi=0
$$

and Neumann boundary conditions at the contour $\partial S$ of the cavity cross-section

$$
\frac{\partial \Psi}{\partial n}=0,
$$

where $k_{\perp}=\sqrt{k^{2}-k_{z}^{2}}$ is the transverse wavenumber of TE mode, which far exceeds the axial wavenumber $k_{z}$ in gyrotrons, $k=\omega / c, \omega$ is the frequency of TE mode, vector $\mathbf{n}$ is the outward normal to the contour $\partial S$. In (1) and (2), the factor of the form $\exp \left(-i \omega t+i k_{z} z\right)$ is assumed and suppressed.

To solve the eigenvalue problem (1) and (2) we turn to the widely-accepted rigorous method of spatial harmonics (SHM) [6]. According to this method, the electromagnetic field in the waveguide channel (domain 1) and corrugations (domain 2) is expressed in terms of spatial Bloch and Fourier harmonics, respectively. In 
particular, the membrane function $\Psi$ in domains 1 and 2 (see Fig. 1) is written as

$$
\left\{\begin{array}{l}
\Psi_{1}=\sum_{n=-\infty}^{\infty} A_{n} f_{n}(r) e^{i k_{n} \varphi}, 0<r<R_{0} \\
\Psi_{2}=\sum_{l=0}^{\infty} X_{l} g_{l}(r) \cos \left(\xi_{l}\left(\varphi+\frac{\varphi_{L}}{2}\right)\right), R_{0}<r<R_{d}
\end{array}\right.
$$

where $f_{n}(r)=J_{k_{n}}\left(k_{\perp} r\right) / J_{k_{n}}^{\prime}\left(k_{\perp} R_{0}\right), k_{n}=m+n N, m$ is the azimuthal mode index, $n$ is the number of Bloch harmonic, $N$ is the number of corrugations, $\xi_{l}=\pi l / \varphi_{L}$,

$$
g_{l}(r)=\frac{J_{\xi_{l}}\left(k_{\perp} r\right) N_{\xi_{l}}^{\prime}\left(k_{\perp} R_{d}\right)-J_{\xi_{l}}^{\prime}\left(k_{\perp} R_{d}\right) N_{\xi_{l}}\left(k_{\perp} r\right)}{J_{\xi_{l}}^{\prime}\left(k_{\perp} R_{0}\right) N_{\xi_{l}}^{\prime}\left(k_{\perp} R_{d}\right)-J_{\xi_{l}}^{\prime}\left(k_{\perp} R_{d}\right) N_{\xi_{l}}^{\prime}\left(k_{\perp} R_{0}\right)} .
$$

The eigenvalue for TE mode of the corrugated gyrotron cavity is found from the continuity conditions imposed on the membrane function $\Psi$ and its derivative $d \Psi / d r$ at the interface between domains 1 and 2. In general, theses conditions lead to the coupling between spatial harmonics. In [7], SHM has been adopted to investigate the effect of mode coupling on eigenvalues and eigenfields of a cylindrical gyrotron cavity with longitudinal wall corrugations. In addition to that, the ohmic wall losses in this cavity have been studied using the perturbation approach $[2,4]$. In this approach [8], the complex transverse wavenumber is written as

$$
k_{\perp}^{2} \approx k_{\perp 0}^{2}\left[1-\frac{(1+j) \delta}{2} \frac{\oint_{\partial S}|\Psi|^{2} d l}{\int_{S}|\Psi|^{2} d S}\right],
$$

where $k_{\perp 0}$ is the real transverse wavenumber of the perfectly conducting (lossless) cavity, $S$ is the crosssectional area of the cavity, $\delta=\sqrt{2 / \omega \mu_{0} \sigma}$ is the skindepth, $\sigma$ is the wall conductivity.

The power of ohmic losses in the gyrotron cavity is inversely proportional to the ohmic Q-value, which has the following form

$$
Q_{O h m}=\frac{\operatorname{Re}\left(k_{\perp}\right)}{2 \operatorname{Im}\left(k_{\perp}\right)} .
$$

In the following, we will investigate the ohmic losses in relation to geometrical parameters of the corrugated gyrotron cavity with the aim to maximize the ratio between ohmic Q-values of the operating and competing modes. For this purpose we consider the fundamental $\mathrm{TE}_{4,5}$ mode, which is the most dangerous competing mode in the $0.4-\mathrm{THz}$ second-harmonic gyrotron operated in the $\mathrm{TE}_{8,9}$ mode [2].

\section{OHMIC LOSSES IN LONGITUDINALLY CORRUGATED CAVITIES}

Initial parameters of the corrugated gyrotron cavity are as follows [2]: the cavity radius $R_{0}=0.45 \mathrm{~cm}$, the number of corrugations $N=20, \varphi_{L} / \varphi_{S}=0.5$. The cavity is assumed to be made of copper with reduced conductivity $\sigma=2.9 \times 10^{7} \mathrm{~S} / \mathrm{m}$ due to surface roughness.

The frequency $f_{8,9}$ of the operating secondharmonic $\mathrm{TE}_{8,9}$ mode is close to twice that $2 f_{4,5}$ of the fundamental competing $\mathrm{TE}_{4,5}$ mode. This is evident from Fig. 2.

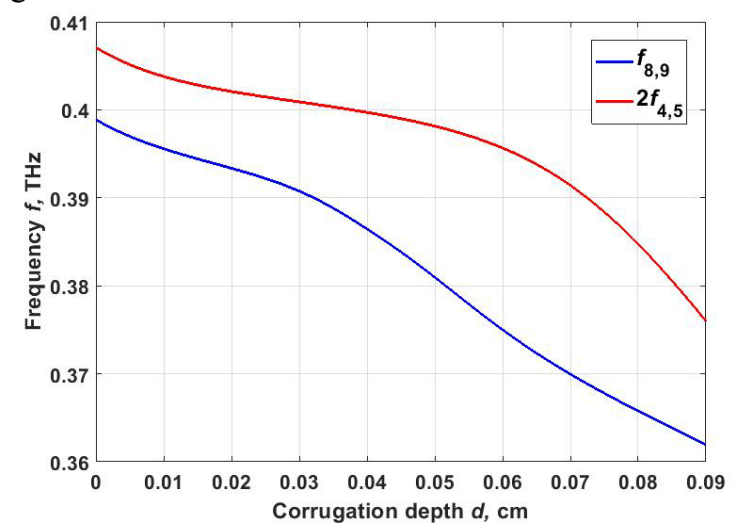

Fig. 2. Frequencies $f_{8,9}$ and $2 f_{4,5}$ versus the corrugation depth $d=R_{d}-R_{0}$ for corrugated waveguide with $N=20$

Fig. 3 shows the dependence of the ohmic Q-value (solid lines) on the corrugation depth for the operating and competing modes. It is seen that ohmic losses of the $\mathrm{TE}_{8,9}$ и $\mathrm{TE}_{4,5}$ modes increase with $d$. It is interesting to note that this increase has a nonmonotonic behavior for the operating second-harmonic mode.

Determine the ratio between the ohmic Q-values of the operating and competing modes as

$$
f_{Q}=\frac{Q_{O h m 8,9}}{Q_{O h m 4,5}} \text {. }
$$

Dashed line in Fig. 3 shows $f_{Q}$ (normalized to its value at $d=0$ ) as a function of the corrugation depth. This function has a clear-cut maximum in the vicinity of $d \approx 0.08 \mathrm{~cm}$. This maximum corresponds to the most distinct increase in relative difference between the ohmic losses of the competing $\mathrm{TE}_{4,5}$ mode and the operating $\mathrm{TE}_{8,9}$ mode, and thus implies the most efficient selective suppression of the fundamental competitor for $N=20$.

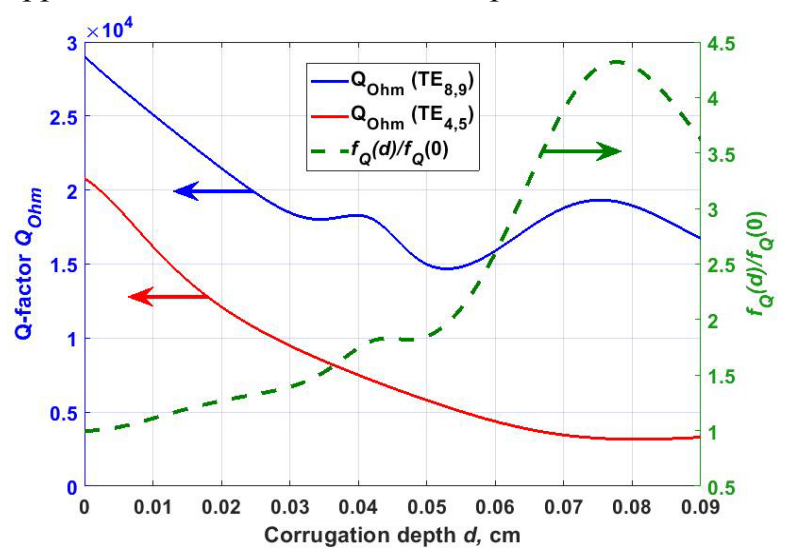

Fig. 3. Ohmic $Q$-factors of the $T E_{8,9}$ and $T E_{4,5}$ modes and their normalized ratio $f_{Q}$ versus the corrugation depth $d$

for cylindrical corrugated waveguide with $N=20$

Despite this, the corrugation parameters $N=20$ and $d \approx 0.08 \mathrm{~cm}$ can be nonoptimal. The reason lies in conversion of the operating $\mathrm{TE}_{8,9}$ mode (fundamental Bloch harmonic) to higher Bloch harmonics. Such mode conversion is possible, if the number of corrugations is not large enough $[5,7]$. This effect is undesirable, since, compared to the operating mode, higher Bloch harmon- 
ics have much weaker coupling to the electron beam in gyrotron cavity [9]. As a consequence, for secondharmonic gyrotron mode conversion can make efficient operation hardly feasible.

To investigate mode conversion for azimuthal modes of a corrugated waveguide, we introduce the following parameter

$$
\alpha_{n}=\frac{P_{n}}{P}
$$

where $P=\sum_{n=-\infty}^{\infty} P_{n}, \quad P_{n}=2 \pi\left|A_{n}\right|^{2} \int_{0}^{R_{0}} J_{k_{n}}^{2}\left(k_{\perp} r\right) r d r$. It is clear that conversion of the operating mode to higher Bloch harmonics is absent for $\alpha_{0}=1(n=0)$.

Fig. 4 shows $\alpha_{n}$ versus corrugation depth for several coupled azimuthal modes. It is seen that for $N=20$ increase in depth $d$ is accompanied by conversion of the operating $\mathrm{TE}_{8,9}$ mode to higher Bloch harmonics, mostly to those with $n= \pm 1$. This unwanted phenomenon can be avoided by increase in the number of corrugations $[5,7]$.

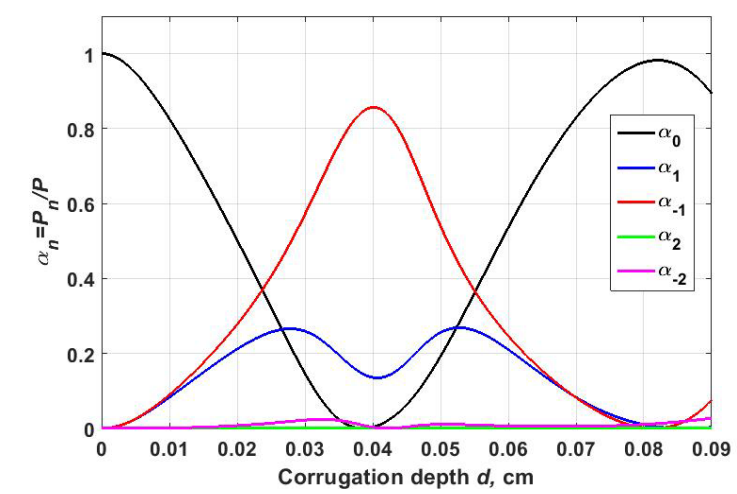

Fig. 4. Parameter $\alpha_{n}$ as a function of the corrugation depth $d$ for coupled Bloch harmonics of a cylindrical corrugated waveguide with $N=20$

Fig. 5 shows the dependence $f_{Q}(d)$ for $N$ equal to 40,50 , and 60 . The maximum of $f_{Q}(d)$, which implies the improved mode selection in the gyrotron cavity, is seen for $N=50$ and $N=60$, and is attained at the corrugation depth $d \approx 0.035 \mathrm{~cm}$.

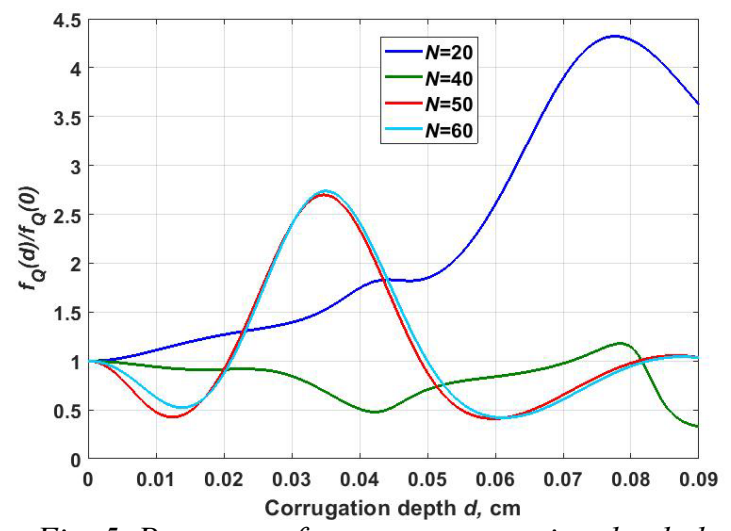

Fig. 5. Parameter $f_{Q}$ versus corrugation depthd for different number $N$ of corrugations

Let us look more closely into these parameters of corrugations. Fig. 6,a depicts the cavity eigenfrequency versus the number of corrugations for the fixed value of $d=0.035 \mathrm{~cm}$. One can see that the frequency changes irregularly for $N<40$. Such frequency behavior is relative to coupling between different Bloch harmonics. This can be clearly seen graphically in Fig. 6,b. Effect of mode conversion on ohmic losses in the corrugated gyrotron cavity is shown in Fig. 6,c.
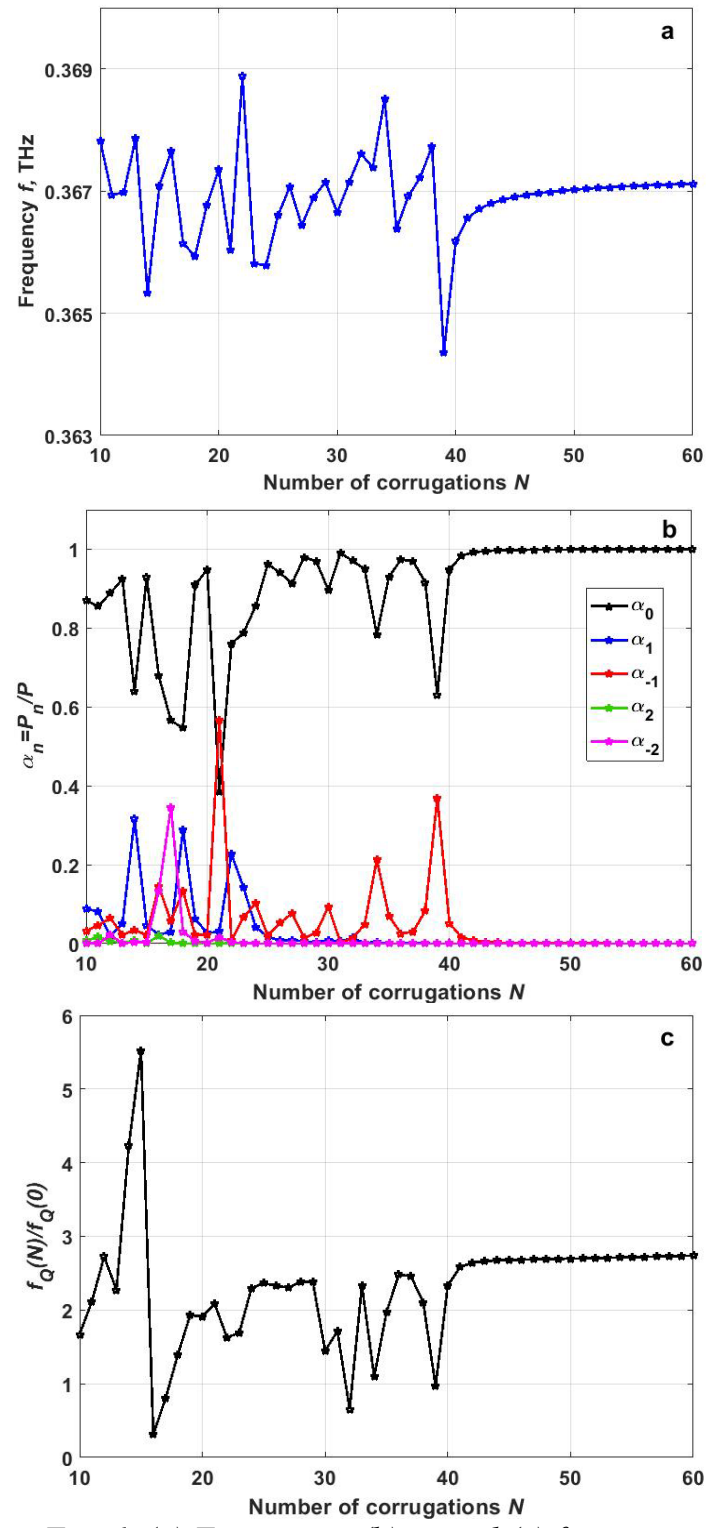

Fig. 6. (a) Frequency, (b) $\alpha_{n}$ and (c) $f_{Q}$ versus the number of corrugations $N$ for $d=0.035 \mathrm{~cm}$

From the above discussion it follows that the most effective mode selection in the corrugated cavity of a second-harmonic gyrotron requires $\alpha_{0}$ to be close to unity and $f_{Q}$ to be as high as possible. As Fig. 6 suggests, the number of corrugations in excess of 45 fulfils these requirements for $R_{0}=0.45 \mathrm{~cm}, \varphi_{L} / \varphi_{S}=0.5$ and $d=0.035 \mathrm{~cm}$. For $N=45$ the corrugations width equals $w \approx 0.031 \mathrm{~cm}$. In this case, for the $0.4-\mathrm{THz}$ second-harmonic gyrotron the ratio between the ohmic Qvalues of the operating $\mathrm{TE}_{8,9}$ mode and competing $\mathrm{TE}_{4,5}$ mode of the corrugated cavity exceeds that of the smooth cavity $(d=0)$ by a factor of 2.7 . 


\section{CONCLUSIONS}

It has been shown that ohmic losses in the corrugated cavity of the second-harmonic gyrotron can be used for selective suppression of unwanted modes excited at the first cyclotron harmonic. To attain this aim, it is necessary to select the corrugation parameters (their number, depth and width) in such a way as to maximize the ohmic losses for the fundamental competing modes and to maintain low losses for the operating mode. As an example, influence of the depth and number of corrugations on ohmic Q-values has been studied for the operating second-harmonic $\mathrm{TE}_{8,9}$ mode and the most dangerous fundamental competing $\mathrm{TE}_{4,5}$ mode of the 0.4-THz second-harmonic gyrotron. Parameters of corrugations are found for maximum ratio between ohmic Q-values of the operating and competing modes. Such a ratio corresponds to the most effective suppression of the fundamental competing $\mathrm{TE}_{4,5}$ mode. We have determined the required number of corrugations, which do not produce conversion of the operating mode to higher Bloch harmonics and therefore have little effect on the efficiency of $0.4-\mathrm{THz}$ gyrotron operated in the secondharmonic $\mathrm{TE}_{8,9}$ mode.

\section{REFERENCES}

1. T. Idehara, S.P. Sabchevski. Gyrotrons for highpower terahertz science and technology at FIR UF // J. Infrared Milli. Terahz. Waves. 2016, v. 38, № 1, p. 62-86.

2. V.I. Shcherbinin, V.I. Tkachenko. Cylindrical cavity with distributed longitudinal corrugations for second-harmonic gyrotrons // J. Infrared Milli. Terahz. Waves. 2017, v. 38, № 7, p. 838-852.
3. V.I. Shcherbinin, A.V. Hlushchenko, A.V. Maksimenko, V.I. Tkachenko. Effect of cavity ohmic losses on efficiency of low-power terahertz gyrotron // IEEE Trans. Electron Devices. 2017, v. 64, № 9, p. 3898-3903.

4. V.I. Shcherbinin, B.A. Kochetov, A.V. Hlushchenko, V.I. Tkachenko. Cutoff frequencies of a dielectricloaded rectangular waveguide with arbitrary anisotropic surface impedance // IEEE Trans. Microw. Theory Techn. 2019, v. 67, № 2, p. 577-583.

5. T.I. Tkachova, V.I. Shcherbinin, V.I. Tkachenko. Validity of surface impedance model for electromagnetic analysis of a corrugated gyrotron cavity // Proc. Int. Conf. Math. Methods Electromagn. Theory (MMET'2018), Kyiv, Ukraine, 2-5 July 2018, p. 238-241.

6. Z.C. Ioannidis, K.A. Avramides, G.P. Latsas, I.G. Tigelis. Azimuthal mode coupling in coaxial waveguides and cavities with longitudinally corrugated insert // IEEE Trans. Plasma Sci. 2011, v. 39, № 5, p. 1213-1221.

7. T.I. Tkachova, V.I. Shcherbinin, V.I. Tkachenko. Eigenvalues and eigenfields of a corrugated gyrotron cavity with conducting walls // Problems of Atomic Science and Technology. Series "Plasma Physics". 2018, №6 (118), p. 67-70.

8. B.Z. Katsenelenbaum. High-frequency electrodynamics. Weinheim, Germany: Wiley-VCH, 2006.

9. Z.C. Ioannidis, K.A. Avramidis, I.G. Tigelis. Selectivity properties of coaxial gyrotron cavities with mode converting corrugations // IEEE Trans. Electron Devices. 2016, v. 63, № 3, p. 1299-1306.

Article received 05.04.2019

\section{СЕЛЕКЦИЯ МОД ОМИЧЕСКИМИ ПОТЕРЯМИ В ПРОДОЛЬНО ГОФРИРОВАННЫХ РЕЗОНАТОРАХ СУБ-ТГЦ ГИРОТРОНОВ НА ВТОРОЙ ГАРМОНИКЕ}

\section{Т.И. Ткачева, В.И. Щербинин, В.И. Ткаченко}

Предложено использовать омические потери в стенках для улучшения селекции мод в цилиндрическом резонаторе гиротрона с продольными клиновидными гофрами. Такие потери зависят от частоты моды и геометрии гофров. Для резонатора 0.4-ТГц гиротрона на второй циклотронной гармонике найдена глубина гофров, которая отвечает максимальным омическим потерям конкурирующих мод на первом (фундаментальном) циклотронном резонансе и достаточно низким потерям рабочей моды. Для этой глубины определены количество гофров и их ширина, которые обеспечивают максимальный прирост омических потерь для фундаментальных конкурирующих мод относительно потерь для рабочей моды на втором циклотронном резонансе, а также минимальную конверсию рабочей моды в высшие гармоники Блоха. Параметры гофров могут быть реализованы на практике.

\section{СЕЛЕКЦІЯ МОД ОМІЧНИМИ ВТРАТАМИ В ПОЗДОВЖНЬО ГОФРОВАНИХ РЕЗОНАТОРАХ СУБ-ТГЦ ГІРОТРОНІВ НА ДРУГІЙ ГАРМОНІЩІ}

\section{T.I. Ткачова, В.I. Щербінін, В.І. Ткаченко}

Запропоновано використання омічних втрат у стінках для поліпшення селекції мод у циліндричному резонаторі гіротрона з поздовжніми клиновидними гофрами. Такі втрати залежать від частоти моди та геометpiї гофрів. Для резонатора 0.4-ТГц гіротрона на другій циклотронній гармоніці знайдено глибину гофрів, яка відповідає максимальним омічним втратам конкуруючих мод на першому (фундаментальному) циклотронному резонансі та досить низьким втратам робочої моди. Для цієї глибини визначено кількість гофрів та їх ширину, які забезпечують максимальне збільшення омічних втрат для фундаментальних конкуруючих мод відносно втрат робочої моди на другому циклотронному резонансі, а також мінімальну конверсію робочої моди у вищі гармоніки Блоха. Параметри гофрів можуть бути реалізовані на практиці. 